\title{
STRESS, LO ÂU Ở LÁI XE KHÁCH ĐƯờNG DÀI VÀ TAI NẠN GIAO THÔNG
}

\section{TÓM TẮT.}

Nghiên cứu được tiến hành nhằm tìm hiểu thực trạng stress, lo âu ở lái xe khách đường dài và mối liển quan với tai nạn giao thông. 200 nam lái xe khách đường dài tuyến cố định liên tỉnh với tuổi đời trung

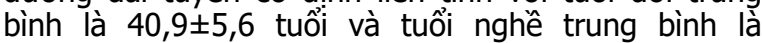
$12,4 \pm 5,6$ năm đã tham gia nghiên cứu. Các lái xe được phân tích đăc điểm công việc; đánh giá mức điểm stress bằng thang SAS, kiểm soát stress tại nơi làm việc bằng thang AIS, đánh giá lo âu bằng test Zung và hồi cứu số liệu tai nạn giao thông trong 3 năm liên tục tai doanh nghiêp.Kết quả nghiên cứu cho thấy: Công việc của lái xe khách đường dài gây căng thẳng thân kinh tâm lý, thời gian lao động kéo dài, chế độ thay ca không ổn định, thường xuyên phải lái đêm, làm việc trong tư thế bất lợi (phải ngồi lâu trong thời gian dài)... Tỷ lệ lái xe khách đường dài có biểu hiện stress là 58,5\%; biểu hiện lo âu là $40,0 \%$. Đa số các lái xe khách kiểm soát được stress công việc $(97,5 \%)$. Nguy cơ tai nạn giao thông ở nhóm lái xe khách đường dài có biểu hiện stress cao gấp 4,2 lần so với nhóm không có biểu hiện stress $(95 \% \mathrm{CI}=1,5-$ $11,7)$. Nguy cơ tai nan giao thông ở nhóm lái xe khách đường dài có biểu hiện lo âu cao gấp 3,0 lần so với nhóm không có biểu hiện lo âu $(95 \% \mathrm{CI}=1,3-6,5)$. Các tác giả khuyến nghị cần áp dụng giải pháp phòng tránh stress, lo âu cho lái xe để góp phân giảm thiểu tai nạn giao thông.

Tư khoá: Lái xe khách đường dài, lo âu, stress, tai nạn giao thông

\section{SUMMARY \\ SITUATION OF SLEEP DISORDER OF LONG DISTANCE DRIVER AND TRAFFIC ACCIDENTS}

This study was carried out to to investigate stress, anxiety of long distance drivers and relationship with traffic accidents. 200 male drivers with $40.9 \pm 5.6$ years of age and $12.4 \pm 5.6$ participated in this study. The drivers are analyzed for job characteristics; investigating stress by AIS questionnnair and evaluating anxiety according to Zung test and retrospective traffic accident data for 3 years at the enterprise. The result showed that: The job characteristics of long distance drivers are high intensity of work; a working long time, unstable time; a night duty; a high responsibility, long sitting hours, ect... The rate of long-distance driver's stress was $58.5 \%$; symptoms of anxiety are $40.0 \%$. Most of longdistance drivers can control their work stress (97.5\%).

*Viện Sức khỏe nghề nghiệp và môi trường

Chịu trách nhiệm chính: Nguyễn Thu Hà

Email: thuhayhld@gmail.com

Ngày nhận bài: 14.5.2021

Ngày phản biện khoa học: 6.7.2021

Ngày duyệt bài: 16.7.2021

\section{Nguyễn Thu Hà*, Nguyễn Đức Sơn*}

In the long-distance driver, the risk of traffic accidents of driver's stress group was 4.2 times higher than that among the non-stressed group ( $95 \% \mathrm{CI}=1.5-11.7)$. The risk of traffic accidents of driver's anxiety group was 3.0 times higher than that among the nonanxiety group ( $95 \%$ CI $=1.3-6.5)$. The author recommended that it is necessary to have solution to prevent stress and anxiety for drivers in order to reducing traffic accidents.

Keywords: Long distance drivers, anxiety, stress, traffic accident

\section{I. ĐẶT VẤN ĐỀ}

Lái xe là một nghề đặc biệt. An toàn khi lái xe là yêu câu, mục tiêu lớn nhất khi tham gia giao thông bởi nó liên quan tới tính mạng của con người (của chính lái xe và những người tham gia giao thông); đặc biệt là xe khách đường dài liên quan tới tính mạng nhiều người - các hành khách trên xe.

Phân tích từ các vụ tai nạn giao thông cho thấy $80 \%$ là do lỗi của người điêu khiển phương tiện giao thông (lái xe). Bởi vậy các yếu tố về con người (yếu tố tâm sinh lý người lái xe...) là một trong những yếu tố quan trọng trong góp phần giảm thiểu tai nạn giao thông; đặc biệt là tình trạng stress, lo âu, mệt mỏi,... ở các lái xe.

Các nhà nghiên cứu ở Đại học Công nghệ Queensland, Australia tìm thây mối quan hệ giữa căng thẳng tâm lý với hành vi lái xe ẩu và mạo hiểm trên đường cũng như những biểu hiện không vững vàng về tâm lý lúc đối mặt với tình trạng tắc nghẽn giao thông. Thói quen lái xe nguy hiểm này, bao gồm cả việc chạy quá tốc độ, không sử dụng dây an toàn và lái xe trong khi sử dụng điện thoại câm tay. Nhóm nghiên cứu phân tích 761 người điêu khiển xe trẻ tuổi cho thâyy có tới $8,5 \%$ trong số họ bị trâm cảm, căng thẳng do thói quen điêu khiển phương tiện giao thông ẩu, không an toàn. "Có một mối liển hệ rõ ràng giữa hành vi lái xe và căng thẳng, trâm cảm" [tham khảo qua 6].

Nghiên cứu của Lotfi S (2017) trên 610 lái xe cho thây các lái xe ở Iran có khuynh hướng cảm xúc dễ bị tai nạn hơn so với những người có cách giải quyết vấn đề và biết cách đối phó với stress $(p<0,001)[2]$.

Mục tiêu nghiên cứu: - Thực trạng stress, lo âu ở lái xe khách đường dài

- Tìm hiêu môi liên quan giữa stress, lo âu ở lái xe khách đường dài và tai nạn giao thông 


\section{II. ĐỐI TƯƠNGG VÀ PHƯƠNG PHÁP NGHIÊN CỨU}

1. Đối tượng nghiên cứu. 200 nam lái xe khách đường dài tuyến cố định liên tỉnh thuộc 5 doanh nghiệp vận tải có hành trình chạy xe qua tuyến quốc lộ $1 \mathrm{~A}$.

\section{Phương pháp nghiên cứu}

2.1. Thiêt kế nghiên cứu: Nghiên cứu mô tả cắt ngang

\subsection{Chỉ tiêu và phương pháp}

2.2.1. Thực trang stress, lo âu ở lái xe khách đường dài

* Trạng thái stress nghề nghiệp:

- Đánh giá mức điểm stress theo thang điểm stress dành cho người Châu á (Stress Assessment Score for Asians) (SAS). Mức điểm stress được phân loại

Mức 1: Mức điểm stress thấp

Mức 2: Mức điểm stress trung bình

Mức 3: Mức điểm stress coa

- Đánh giá kiểm soát stress tại nơi làm việc (Workplace Stress Survey) bằng thang AIS (The American Institute of Stress). Kết quả được phân loại như sau:

Mức 1: Kiểm soát stress trong công việc tốt

Mức 2: Kiểm soát stress trong công việc tương đối tốt

Mức 3: Kiểm soát stress trong công việc có vấn đề

*Trạng thái lo âu: Sử dụng test Zung để đánh giá trạng thái lo âu. Test gồm 20 câu hỏi về các biểu hiện trạng thái tâm lý trong thời gian gần đây. Mỗi câu hỏi có 4 thang trả lời: Không có biểu hiện này; rất hiếm khi; phần lớn thời gian; tất cả thời gian. Tính tổng số điểm thô và điểm phần trăm và phân loại như sau:

Mức 1: Có biểu hiện lo âu (>40 điểm)

Mức 2: Không có biểu hiện lo âu ( $\leq 40$ điểm)

2.2.2. Tìm hiểu mối liên quan rối loạn giấc ngủ ở lái xe khách đường dài và tai nạn giao thông

- Hồi cứu số liệu về tai nạn giao thông tại doanh nghiệp

- Phân tích mối liên quan giữa stress, lo âu ở lái xe khách đường dài và tai nạn giao thông

2.3 Xử lý số liệu theo phương pháp thống kê y học và chương trình phần mềm SPSS 20.0

\section{KẾT QUẢ NGHIÊN CỨU}

3.1. Đặc điểm yêu câu công viêc của lái xe khách đường dài tuyến cố định liên tỉnh

- Thường xuyên làm việc trong môi trường căng thẳng thần kinh tâm lý (công việc đòi hỏi phải có trí nhớ tốt; cần những quyết định nhanh, kịp thời, chính xác, phản ứng nhanh...), dễ gây mệt mỏi, buồn ngư; thiếu kiên nhẫn, bình tĩnh khi lái xe; có nhiều tình huống bất ngờ, yếu tố bất trắc trên đường.

- Thời gian lao động kéo dài, chế độ thay ca không ổn định, thường xuyên phải lái đêm; (các tuyến $<300 \mathrm{~km}$ các lái xe phải lái quay vòng trong ngày; đặc biệt với các tuyến đường dài $>300$ km như tuyến Hà Nội - Sài Gòn)

- Làm việc trong tư thế bất lợi (phải ngồi lâu trong thời gian dài), tiếp xúc với rung toàn thân

3.2 Thực trang stress, lo âu ở lái xe khách đường dài

Bảng 1. Kêt quả tự đánh giá về stress ở lái xe

\begin{tabular}{|c|c|c|c|}
\hline $\begin{array}{c}\text { Tự đánh giá về } \\
\text { stress (n=200) }\end{array}$ & $\begin{array}{c}\text { Số đối } \\
\text { tượng } \\
\text { (n) }\end{array}$ & $\begin{array}{c}\text { Tỷ lề } \\
\text { (\%) }\end{array}$ & $\begin{array}{c}\text { Điếm } \\
\text { trung } \\
\text { bình }\end{array}$ \\
\hline \multicolumn{3}{|c|}{ Phân bố mức điếm stress } \\
\hline Mức điếm stress thấp & 83 & 41,5 & $1,6 \pm 0,9$ \\
\hline $\begin{array}{c}\text { Mức điếm stress trung } \\
\text { bình }\end{array}$ & 104 & 52,0 & $5,7 \pm 0,6$ \\
\hline $\begin{array}{c}\text { Mức điếm stress cao } \\
\text { Điếm trung bình }\end{array}$ & \multicolumn{4}{|c|}{$4,1 \pm 2,5$} & $7,2 \pm 0,4$ \\
\hline \multicolumn{3}{|c|}{ Phân bố tỷ lệ stress ớ lái xe } \\
\hline Có biếu hiện stress & 117 & 58,5 \\
\hline $\begin{array}{c}\text { Không có biếu hiện } \\
\text { stress }\end{array}$ & 83 & 41,5 & \\
\hline
\end{tabular}

Kết quả tự đánh giá về stress ở lái xe cho thấy: $41,5 \%$ lái xe có mức điểm stress ở mức thấp; $52,0 \%$ lái xe có mức điểm stress ở mức trung bình; $6,5 \%$ lái xe có mức điểm stress ở mức cao. Tỷ lệ lái xe khách đường dài có biểu hiện stress là 58,5\%.

Bảng 2. Mức độ kiểm soát stress nghề nghiệp ở lái xe

\begin{tabular}{|c|c|c|c|}
\hline $\begin{array}{c}\text { Mức độ kiếm soát } \\
\text { stress nghề nghiệp } \\
\text { (n= 200) }\end{array}$ & $\begin{array}{c}\text { Số đối } \\
\text { tượng } \\
\text { (n) }\end{array}$ & $\begin{array}{c}\text { Tỷ leê } \\
\text { (\%) }\end{array}$ & $\begin{array}{c}\text { Điểm } \\
\text { trung } \\
\text { bình }\end{array}$ \\
\hline $\begin{array}{c}\text { Kiếm soát tốt stress } \\
\text { Kiếm soát tương đối } \\
\text { tốt stress }\end{array}$ & 86 & 43,5 & $24,7 \pm 9,3$ \\
\hline $\begin{array}{c}\text { Không kiểm soát } \\
\text { được stress }\end{array}$ & 5 & 2,5 & $70,6 \pm 0,5$ \\
\hline
\end{tabular}

Theo bộ câu hỏi đánh giá stress tại nơi làm việc: có $54,5 \%$ lái xe khách kiểm soát stress tốt trong công việc; $43,0 \%$ kiểm soát tương đối tốt stress và chỉ có $2,5 \%$ đang gặp vấn đề stress cần được can thiêp sớm.

Bảng 3. Kêt quả tự đánh giá về trạng thái lo âu ở lái xe

\begin{tabular}{|c|c|c|c|}
\hline $\begin{array}{c}\text { Trạng thái lo âu } \\
\text { (n=200) }\end{array}$ & $\begin{array}{c}\text { Số đối } \\
\text { tượng } \\
\text { (n) }\end{array}$ & $\begin{array}{c}\text { Tỷ lệ̂ } \\
\text { (\%) }\end{array}$ & $\begin{array}{c}\text { Điểm } \\
\text { trung bìnt }\end{array}$ \\
\hline $\begin{array}{c}\text { Không biếu hiện } \\
\text { lo âu }\end{array}$ & 120 & 60,0 & 27,1 \\
$\pm 7,9$ \\
\hline
\end{tabular}




\begin{tabular}{|c|c|c|c|}
\hline Có biếu hiện lo âu & 80 & 40,0 & $41,9 \pm 0,0$ \\
\hline - Mức độ nhẹ & 80 & 100 & \\
\hline - Mức độ vừa & 0 & 0 & \\
\hline - Mức độ nặng & 0 & 0 & \\
\hline
\end{tabular}

Tỷ lệ lái xe khách đường dài có biếu hiện lo âu với mức độ nhẹ qua đánh giá bằng test Żung là $40,0 \%$.

Bảng 4. Một số biểu hiện chính của trạng thái stress, lo âu ở lái xe

\begin{tabular}{|c|c|c|}
\hline $\begin{array}{l}\text { Một số biếu hiện chính } \\
(\mathrm{n}=200)\end{array}$ & $\mathbf{n}$ & $\%$ \\
\hline Mệt mỏi & 134 & 67,0 \\
\hline $\begin{array}{l}\text { Ngủ không ngon và rối loạn } \\
\text { giấc ngủ }\end{array}$ & 133 & 66,5 \\
\hline $\begin{array}{l}\text { Không thích thú với các công } \\
\text { việc hàng ngày }\end{array}$ & 117 & 58,5 \\
\hline $\begin{array}{c}\text { Cảm thấy nóng nảy và lo âu } \\
\text { hơn thường lệ }\end{array}$ & 114 & 57,0 \\
\hline $\begin{array}{l}\text { Không thể nói thật về những suy } \\
\text { nghî̀, quan điểm ơ nơi làm việc }\end{array}$ & 114 & 57,0 \\
\hline $\begin{array}{l}\text { Cảm giác tê cóng và như kiến } \\
\text { bò ở các đầu ngón tay và chân }\end{array}$ & 113 & 56,5 \\
\hline Thường khó ngủ & 112 & 56,0 \\
\hline Đau đầu & 109 & 54,5 \\
\hline Đau mỏi cơ & 153 & 76,5 \\
\hline Cảm thấy yếu và dê mệt mỏi & 108 & 54,0 \\
\hline Hay lo lằng & 102 & 51,0 \\
\hline
\end{tabular}

Một số biểu hiện chính của trạng thái stress, lo âu ở lái xe: Mệt mỏi $(67,0 \%) ;$ Ngủ không ngon và rối loạn giấc ngủ $(66,5 \%)$; Không thích thú với các công việc hàng ngày $(58,5 \%)$; Cảm thấy nóng nảy và lo âu hơn thường lệ $(57,0 \%)$; Không thể nói thật về những suy nghĩ, quan điểm ở nơi làm việc (57,0\%); Cảm giác tê cóng và như kiến bò ở các đầu ngón tay và chân (56,5\%); Thường khó ngủ (56,0\%); Đau đầu $(54,5 \%)$; Đau mỏi cơ $(76,5 \%)$; Cảm thấy yếu và dễ mệt mỏi (54,0\%); Hay lo lắng (51,0\%).

3.3. Tìm hiểu mối liên quan giữa stress, lo âu ở lái xe khách đường dài và tai nạn giao thông

Bảng 5. Hồi cứu về tai nạn giao thông ở các lái xe đường dài

\begin{tabular}{|c|c|c|}
\hline $\begin{array}{c}\text { Hồi cứu về tai nan giao } \\
\text { thông (n=200) }\end{array}$ & $\mathbf{n}$ & $\mathbf{\%}$ \\
\hline $\begin{array}{c}\text { Có số liệu hồi cứu chi tiết về tai } \\
\text { nạn giao thông }\end{array}$ & 132 & 66,0 \\
\hline $\begin{array}{c}\text { Không có số liệu hồi cứu chi tiết } \\
\text { về tai nạn giao thông }\end{array}$ & 68 & 34,0 \\
\hline
\end{tabular}

Trong số 200 lái xe tham gia nghiên cứu, 132 lái xe $(66,0 \%)$ được hồi cứu chi tiết về tai nạn giao thông trong 3 năm qua thông qua quản lý lý lịch cá nhân của lái xe.

Bảng 6. Hồi cứu về tai nạn giao thông trong 3 năm

\begin{tabular}{|c|c|c|c|c|c|c|}
\hline \multirow{2}{*}{ Ghi nhận về tai nạn giao thông (n=132) } & \multicolumn{2}{|c|}{$\mathbf{2 0 1 6}$} & \multicolumn{2}{|c|}{$\mathbf{2 0 1 5}$} & \multicolumn{2}{c|}{$\mathbf{2 0 1 4}$} \\
\cline { 2 - 7 } & $\mathbf{n}$ & $\mathbf{\%}$ & $\mathbf{n}$ & $\mathbf{\%}$ & $\mathbf{n}$ & $\mathbf{\%}$ \\
\hline Số lái xe có ghi nhận tai nạn giao thông & 20 & 15,2 & 21 & 15,9 & 13 & 9,8 \\
\hline Tống số vụ/ lượt ghi nhận tai nạn giao thông & \multicolumn{2}{|c|}{25} & \multicolumn{2}{|c|}{26} & \multicolumn{2}{c|}{16} \\
\hline Số vụ/ lượt lái xe ghi nhận tai nạn giao thông \\
trung bình
\end{tabular}

Số lái xe có ghi nhận tai nạn giao thông năm 2016 là 20/132 (15,2\%); năm 2015 là 21/132 $(15,9 \%)$ và năm 2014 là 12/132 (9,8\%). Tổng số vụ/ lượt ghi nhận tai nạn giao thông có xu hướng gia tăng trong năm 2016 và 2015 hơn so với năm 2014.

Bảng 7. Môi liên quan giữa stress và tai nạn giao thông

\begin{tabular}{|c|c|c|c|c|c|c|c|}
\hline \multirow{2}{*}{ Stress } & \multicolumn{2}{|c|}{ Đã từng TNGT } & \multicolumn{2}{|c|}{ Chưa bị TNGT } & \multirow[b]{2}{*}{$\mathbf{p}$} & \multirow{2}{*}{ OR } & \multirow{2}{*}{$95 \% \mathrm{CI}$} \\
\hline & $\mathbf{n}$ & $\%$ & $\mathbf{n}$ & $\%$ & & & \\
\hline Có stress & 45 & 90,0 & 56 & 68,3 & & & \\
\hline Không & 5 & 10,0 & 26 & 31,7 & $<0,01$ & 4,2 & $1,5-11,1$ \\
\hline Tống ( $n=132)$ & 50 & 100 & 82 & 100 & & & \\
\hline
\end{tabular}

Nguy cơ tai nạn giao thông ở nhóm lái xe khách đường dài có biểu hiện stress cao gấp 4,2 lần so với nhóm không có biểu hiện stress (90,0\% so với 68,3\%; p<0,01;95\%CI=1,5-11,7).

Bảng 8. Môi liên quan giữa lo âu và tai nạn giao thông

\begin{tabular}{|c|c|c|c|c|c|c|c|}
\hline \multirow{2}{*}{ Lo âu } & \multicolumn{2}{|c|}{ Đã từng TNGT } & \multicolumn{2}{|c|}{ Chưa bi TNGT } & \multirow[b]{2}{*}{$\mathbf{p}$} & \multirow{2}{*}{ OR } & \multirow{2}{*}{$95 \% \mathrm{CI}$} \\
\hline & $\mathbf{n}$ & $\%$ & $\mathbf{n}$ & $\%$ & & & \\
\hline Có lo âu & 38 & 76,0 & 42 & 51,2 & \multirow{3}{*}{$<0,01$} & \multirow{3}{*}{3,0} & \multirow{3}{*}{$1,3-6,5$} \\
\hline Không & 12 & 24,0 & 40 & 48,8 & & & \\
\hline Tống $(n=132)$ & $\mathbf{5 0}$ & 100 & 82 & 100 & & & \\
\hline
\end{tabular}

Nguy cơ tai nạn giao thông ở nhóm lái xe khách đường dài có biểu hiện lo âu cao gấp 3,0 lần so với nhóm không có biểu hiện lo âu $(76,0 \%$ so với 51,2\%; $\mathrm{p}<0,01 ; 95 \% \mathrm{CI}=1,3-6,5)$. 


\section{BÀN LUÂ̂N}

Nghiên cứu của Lai SK (2001) [1] chỉ ra mệt mỏi, stress ở lái xe là nguyên nhân chính gây ra tai nạn đường bộ và có liên quan đến an toàn đường bộ. Suhr K (2017) [5] nghiên cứu trên 653 sinh viên đại học được tham gia và yêu cầu hoàn thành nhiều bảng cẩu hỏi đo lường sự giận dữ, suy nghĩ, sự tức giận khi lái xe và hành vi lái xe nguy hiểm. Nghiên cứu này có thể giúp hiểu được quá trình nhận thức ảnh hưởng đến hành vi lái xe khác nhau như thế nào và giúp phát triển các phương pháp để hướng sự chú ý vào các hành vi lái xe an toàn.

Shahar A (2009) [4] kiểm tra các hành vi của 120 nam lái xe Israeli. Kết quả cho thấy các hành vi lái xe nguy hiểm có nguy cơ cao hơn ở những người có mức độ lo lắng, stress cao. Các lái xe ở Toronto được báo cáo sự phân biệt đối xử hàng ngày ở nơi làm việc nhiêu hơn [tham khảo qua 113]. Đây cũng là một trong những nguyên nhân gây stress nghề nghiệp

Theo Jayatilleke AU (2009) thời gian làm việc và tiền lương thấp là yếu tố nguy cơ đối với tai nạn xe buýt trong huyện Kandy, Sri Lanka [tham khảo qua 6].

Còn nghiên cứu của Pourabdian S (2013) thực hiện trên 168 lái xe có tai nan cho thây điểm trẩm cảm có liên quan đáng kể với hành vi lái $x e$, đặc biệt là lỗi sai sót và có liên quan nghịch với tuổi $(p<0,01)$ [3].

\section{KẾT LUÂ̂N}

- Tỷ lệ lái xe khách đường dài có biểu hiên stress là $58,5 \%$. Đa số các lái xe khách kiểm soát được stress công việc $(97,5 \%)$. Nguy cơ tai nạn giao thông ở nhóm lái xe khách đường dài có biểu hiện stress cao gấp 4,2 lần so với nhóm không có biểu hiện stress ( $95 \% \mathrm{CI}=1,5-11,7)$.

- Tỷ lệ lái xe khách đường dài có biểu hiện lo âu là $40,0 \%$. Nguy cơ tai nạn giao thông ở nhóm lái xe khách đường dài có biểu hiện lo âu cao gấp 3,0 lần so với nhóm không có biểu hiện lo âu $(95 \% \mathrm{CI}=1,3-6,5)$.

\section{KHUYẾN NGH!}

Các tác giả khuyến nghị cần áp dụng giải pháp phòng tránh stress, lo ẩu cho lái xe để góp phần giảm thiểu tai nạn giao thông.

\section{TÀI LIỆU THAM KHẢO}

1. Lai SK, Craiq A (2001), A critical review of the psychophysiology of driver fatigue. Biol Psychol. 2001 Feb; 55(3):173-94

2. Lotfi S, Yazdanirad S, Pourabdiyan S, Hassanzadeh A, Lotfi A (2017). Iranian Drivers Based on Driver Coping Styles. Int J Prev Med. 2017 Jul 4;8:52.

3. Pourabdian S, Azmoon H (2013). The Relationship between Trait Anxiety and Driving Behavior with Regard to Self-reported Iranian Accident Involving Drivers. Int J Prev Med. 2013 Oct; 4(10):1115-21.

4. Shahar A (2009) Self-reported driving behaviors as a function of trait anxiety. Accid Anal Prev. 2009 Mar; 41(2):241-5.

5. Suhr KA, Dula CS (2017). The dangers of rumination on the road: Predictors of risky driving. 10.1016/j.aap.2016.10.026. Epub 2016 Nov 26.

6. The Royal society for the prevention od accidents (ROSPA) (2001), Driver fatigue and road accidents a literature review and position paper february.

\section{ĐÁNH GIÁ SƯ ĐÁP ỨNG CỦA TEST KÍCH THÍCH THẦN KINH LẶP LẠI LIỀn TIẾP Ở BỆNH NHÂN NHƯỢC CO' THỂ MẮT}

\section{TÓM TẮT}

Mục tiêu: Nhận xét sự đáp ứng của test kích thích thân kinh lặp lại liên tiếp ở bệnh nhân nhược cơ thể mắt. Đối tượng và phương pháp: 43 bệnh nhân (BN) nhược cơ thể mắt có kháng thể kháng thụ thể acetylcholin dương tính hoặc dương tính với test neostigmin. Kết quả: Tuổi khởi phát trung bình bệnh

\footnotetext{
${ }^{1}$ Đại học Y Hà Nội

2Trung tâm Thần kinh-Bênh viẹn Bạch Mai

Chịu trách nhiệm chính: Nguyễn Văn Tuận

Email: ngtuan21965@gmail.com

Ngày nhận bài: 18.5.2021

Ngày phản biên khoa hoc: 7.7.2021

Ngày duyệt bài: 19.7.2021
}

\section{Triệu Thị Tạo ${ }^{1}$, Nguyễn Văn Tuận ${ }^{2}$}

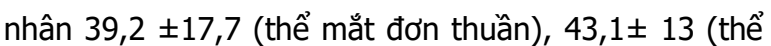
lan toàn thân), thời gian từ khi xuất hiện nhược cơ ở mắt lan toàn thân là $18,9 \pm 59,7$ tháng. Test kích thích thần kinh liên tiếp (KTTKLT) dương tính ở 28 BN $(65,1 \%)$, tỷ lệ dương tính ở nhược cơ thể mắt 30,2\%, độ nhạy $30,8 \%$, nhóm toàn thẩn độ nhạy $80 \%$. Độ nhạy KTTKLT của từng cơ cũng khác nhau tùy nhóm cơ: cơ thang $(61,5 \%)$, cơ vòng mi $(53,8 \%)$, cơ dang ngắn ngón cái $(30,8 \%)$, cơ dạng ngón út $(38,5 \%)$, đến giai đoạn tiến triển sang toàn thân có độ nhạy cao hơn lần lượt $90 \%, 86,7 \%, 80 \%, 66,7 \%$. Kích thích thần kinh liên tiếp có mối liên quan với mức độ nặng trên lâm sàng theo phân đô Osserman $(P=0,001)$. Kết luận: Test kích thích thần kinh liên tiếp là xét nghiệm đơn giản, thuân lợi có thể giúp chẩn đoán bệnh nhược cơ thể mẳt được nhanh hơn và có thể 